\title{
Análise da produção do conhecimento sobre Processo de Enfermagem no Brasil: uma revisão integrativa.
}

Amanda Berlandi dos Santos (IC), Keny Michelly Camargos Ferraz (IC), Erika Christiane Marocco Duran (PQ)

Resumo

Objetivo: Analisar a produção do conhecimento em processo de enfermagem (PE), caracterizando os artigos selecionados segundo 0 ano de produção, delineamento metodológico e tendências temáticas Método: foi realizada uma revisão integrativa de literatura norteada pela seguinte questão: "O que está sendo produzido em relação ao PE na literatura científica brasileira?", por meio de artigos indexados nas bases BDENF, LILACS e MEDLINE. Resultado: o delineamento mais utilizado foi a Fenomenologia; houve um incremento na produção dos artigos relacionado ao PE a partir de 2009 e a queda na produção observada entre 2011 e 2012 pode ser devida a demora dos periódicos em analisar os artigos submetidos. Conclusão: a análise dos dados está em andamento.

Palavras Chave: processos de enfermagem, classificação de enfermagem, pesquisa em enfermagem.

\section{Introdução}

O Processo de Enfermagem (PE) pode ser caracterizado como uma metodologia dinâmica, flexível, organizada e utilizada na prática clínica da enfermagem, para orientar 0 trabalho do enfermeiro na investigação dos dados do paciente, caracterizando as necessidades de cuidado, sugerindo intervenções e avaliando os resultados dos cuidados. ${ }^{1-3}$

Os sistemas de classificação em Enfermagem existem para padronizar a linguagem, facilitando o processo de ensino e aprendizagem, o desenvolvimento de pesquisas e a promoção científica do cuidado. Entre eles destacam-se a Taxonomia II da NANDA Internacional; a Classificação dos Resultados de Enfermagem (NOC); a Classificação das Intervenções de Enfermagem (NIC), entre outros. ${ }^{4}$

A análise da produção do conhecimento permite, além de conhecer e sistematizar o que foi produzido em determinado período de tempo acerca de algum assunto, identificar quais são os temas mais recorrentes abordados sobre 0 mesmo, bem como perceber lacunas e temas ainda inexplorados na área analisada, de modo a configurar como um instrumento norteador que direcione as pesquisas a serem realizadas de acordo com a demanda encontrada. ${ }^{5-6}$

\section{Resultados e Discussão}

A maioria dos artigos analisados tem um delineamento metodológico qualitativo - usado em diversas áreas do conhecimento em enfermagem $^{7}$-, sendo a fenomenologia a mais utilizada pelos pesquisadores deste assunto em questão.

Nota- se uma grande lacuna na produção de artigos referentes ao PE entre os anos de 1993 à 2002, e a partir deste último ano a produção passou a aumentar anualmente. Tais dados podem estar relacionados com o fato de que até 2009 a implantação do PE nas instituições de saúde, públicas ou privadas, era facultativa até a resolução COFEN 358/2009 tornar esta ação obrigatória.

Nos anos de 2011 e 2012 houve um decréscimo da produção dos artigos, o que pode ser devido à demora das revistas em analisar os artigos após a data de submissão ${ }^{1}$, o que justificaria o aumento da produção no ano de 2013.

\section{Conclusões}

A análise dos dados está em andamento.

\section{Agradecimentos}

